\title{
VALUE CO-CREATION THROUGH SOCIAL MEDIA: A CASE STUDY OF A START-UP COMPANY
}

\author{
Junic KIM ${ }^{1}$, Hwanho $\mathrm{CHOI}^{2 *}$ \\ ${ }^{1}$ School of Business, Konkuk University, Seoul, Republic of Korea \\ ${ }^{2}$ School of Business, Ajou University, Suwon, Republic of Korea
}

Received 14 December 2017; accepted 28 September 2018

\begin{abstract}
This research examines social media users' value-creation processes and the drivers of a start-up company's successful social media strategy. This research primarily aims to understand start-ups' effective utilization of social media and value co-creation processes. Although utilizing social media has become key for many organizations, start-ups and small businesses often suffer from a lack of understanding and knowledge of the utilization of social media tools. Therefore, this article uses a case study on the relationship between a social media platform and users' value co-creation to offer a conceptual framework for start-ups to consider in utilizing social media. Our research reveals that four core drivers of social media success include experience, satisfaction, expression, and sharing ability. Each of these drivers in turn contains conditions for understanding users' value-creation process and the creation of drivers for successful social media strategies. The research contributes to literature by providing a detailed review of users' value co-creation as a part of a start-up's successful social media strategy.
\end{abstract}

Keywords: social media, social media strategy, value co-creation, value creation, start-ups, core drivers.

JEL Classification: L10, L26, L82, M15, M30.

\section{Introduction}

A rapidly growing trend in today's business environment is the prominence of social media, which has affected both marketing and innovation strategies (Hollebeek, Glynn, \& Brodie, 2014). This phenomenon has also changed the manner in which companies interact and maintain relationships with users of social media to promote innovation (Kaplan \& Haenlein, 2010). Simultaneously, our perceptions of who these users are and their capabilities have changed; specifically, users are now involved in activities that create value for many companies (Choi \& Burnes, 2013). This phenomenon is particularly active in social media. Further, it is argued that social media can offer companies substantial benefits and innovative work

*Corresponding author. E-mail: hchoi@ajou.ac.kr 
(Papagiannidis \& Bourlakis, 2015), which include new ways of interacting and communicating with users to co-create value (Lusch \& Nambisan, 2015).

However, despite the focus on social media leverage, start-ups and small businesses often suffer from a lack of understanding and knowledge of the utilization of social media tools (Fischer \& Reuber, 2011). Although substantial research points to successful strategies and the key features of social media to manage businesses in the current age of value co-creation, research is still scarce regarding how small businesses and start-ups can better utilize social media and user participation. Further, few companies have achieved viable results, as many have faced challenges in creating strategies to tap social media's potential. Many companies have also struggled to adapt to an environment requiring more open and collaborative relationships (Kaplan \& Haenlein, 2010).

Therefore, this research primarily aims to understand the effective utilization of social media as well as the value co-creation process for social media in start-ups. In this regard, we would like to: 1) investigate how to co-create value through social media, and 2) identify the drivers of a start-up company's successful social media strategy. Our research is distinct and differs from previous studies - which focus on where value co-creation occurs in Web 2.0 in the following three ways: First, while most preceding social media studies either directly or indirectly focus on challenges and market opportunities in social media (Kaplan \& Haenlein, 2010; Mangold \& Faulds, 2009), we describe the exact drivers of a company's successful use of social media. Second, we investigate social media's importance for start-up firms in terms of value co-creation; in this case, the interaction between users and firms is a bilateral process. Third, our study offers empirical evidence of the importance of this alignment. We contribute to literature by providing an in-depth review of users' value co-creation process as a part of a start-up's implementing a successful social media strategy.

The rest of the article is organized as follows. First, we discuss existing literature and present our theoretical understanding of social media, start-ups, and related concepts. By drawing from literature on both social media marketing and value co-creation, we investigate the successful drivers of social media strategies for small companies as well as the conditions for each driver. This is followed by a description of our case organization, a brief discussion of this study's methodology, and our interpretation of the case study's data relative to social media and innovation. We accomplish our research objective through an in-depth case study of value co-creation through social media, then propose a conceptual framework to understand social media users' value-creation processes and small companies' creation of the successful drivers of social media strategies. We conclude with a discussion on this study's limitations and future research directions, as well as a recapitulation of the research's key contributions.

\section{Theoretical foundation: social media and value co-creation}

Value creation involves a symbiotic relationship between companies and users (Kohli \& Grover, 2008; Polese, Mele, \& Gummesson, 2017) through the customization and co-production of products or services (Payne, Storbacka, \& Frow, 2008). Partnership and collaboration help increase companies' value (Swaminathan \& Moorman, 2009). According to Prahalad and Ramaswamy (2004), value co-creation is the personalized interaction between companies and 
users. Firms have discovered the benefits of jointly working with users or customers, such that customers can be agents of value creation, which can lead to a trend of co-creating value (Kohli \& Grover, 2008; Prahalad \& Ramaswamy, 2004). Specifically, the current emerging view is that personal experiences - or users' abilities to assign their own meanings, experiences, and contexts- and sharing them with others, are key in value creation. Therefore, value is regarded as co-created with the different actors in a social media space, including its service providers, the service beneficiaries, and other users (Brodie, Ilic, Juric, \& Hollebeek, 2013; Teixeira et al., 2012). In this context, all businesses' mission should be to serve users rather than produce output (Lusch \& Nambisan, 2015). This changing nature of value and value creation becomes a critical contributor to innovation (Edvardsson, Tronvall, \& Gruber, 2011; Helkkula, Kelleher, \& Pihlström, 2012), and thus, value creation signifies a system in which "actors create and recreate through their effectual actions" (Lusch \& Nambisan, 2015, p. 156). Companies under this context cannot merely regard their produced outputs as complete objects, as this omits the possibility of innovation, improvement, and change through understanding users' experiences with their products or services.

Social media as a channel specifically offers new opportunities for companies to innovate, which can then lead to their improved credibility, success, and sustainability (Bernoff \& Schadler, 2010; Mount \& Martinez, 2014). Companies have been known to utilize social media to create new business opportunities and strategic management practices while improving organizational effectiveness by reconfiguring their existing business resources and practices (Ngai, Tao, \& Moon, 2015). Additionally, utilizing social media has positively affected firms' networking competencies and customer relationship management (Ghezzi, Gastaldi, Lettieri, Martini, \& Corso, 2016; Trainor, Andzulis, Rapp, \& Agnihotri, 2014). With the expectation of these benefits, social media platforms offer the possibility of collaborating with consumers and enhancing consumer loyalty (Brodie et al., 2013; Mount \& Martinez, 2014). For instance, Netflix is a rapidly growing entertainment company that has utilized social media to promote its services and communicate with its core users. Netflix uses social media as a primary channel to promote its content to its core users and decrease costs rather than rely on traditional media channels, such as television. Additionally, Netflix releases all its series' episodes simultaneously, which forces the brand's social media marketing team to take their strategy to another level. The company has consequently been able to co-create value and collaborate with its users through active fan participation in diverse activities, such as developing new products, upgrading its existing content, and participating in social media marketing campaigns (Perlberg, 2015; Williams, 2017). In terms of upgrading its existing products, Netflix is constantly improving the performance of its services and content through users' feedback, which also increases brand loyalty.

Therefore, firms endeavoring to utilize social media must first understand that using social media requires marketing and promotional strategies that transcend traditional norms (Edelman, 2010), as consumers in the social media age act differently from consumers in the traditional media era. Today, social media significantly influences consumers' decisions, as it enables new ways for them to collect and evaluate information from others. Firms are required to acknowledge that they cannot achieve their organizational goals by merely managing corporate-driven or sponsored social media activities. They must understand the power 
of the individual consumer's influence in the social media age, as consumers are now the agents in charge of the online arena (Dimitriu \& Guesalaga, 2017; Mangold \& Faulds, 2009).

In addition to social media's growing popularity among consumers, its utilization by start-ups and small companies is a critical strategy to enhance firms' capabilities and business performance (Ghezzi et al., 2016; M. Lee, M. Lee, \& Kim, 2017). Currently, SMEs are achieving their goals by using social media in various business practices, such as customer relationship management, market research, and knowledge management. These efforts enable small companies to gain operational efficiency, effectively allocate resources, enhance communication, and provide customized offerings (Atanassova \& Clark, 2015).

However, using social media for core business and management purposes, such as innovation, requires careful strategic planning and clear business objectives. Small firms often perceive social media as supplementary marketing, and do not know how to measure its performance (Atanassova \& Clark, 2015). Specifically, small firms lack significant financial resources compared to larger firms (Burnes \& Choi, 2015). Notably, start-ups use a distinct form of value co-creation (Kohli \& Grover, 2008; Ceccagnoli, Forman, Huang, \& Wu, 2011), which can be instrumental in creating a product or a service (Kohli \& Grover, 2008). As start-ups intrinsically have limited available resources (Cavusgil \& Knight, 2015), they must not only create value, but also co-create value with users to promote efficient, radical business growth. Firms can utilize the interactive social media environment to obtain customers' feedback and insights, which can be a critical source for future innovations, as in product development (Rathore, Ilavarasan, \& Dwiedi, 2016). Thus, firms can utilize social media as a strategic tool to improve firm performance, revenues, and their competitive advantage (Aral \& Weill, 2013; Oh, Roumani, Nwankpa, \& Hu, 2017). Further, Brodie et al. (2013, p. 105) argue that "engaged consumers exhibit enhanced consumer loyalty, satisfaction, empowerment, connection, emotional bonding, trust and commitment." Therefore, social media plays a critical role in start-ups' co-creating of value with their users (Atanassova \& Clark, 2015).

This contrasts the notion that value is solely produced through firms' traditional in-house market research to satisfy consumer needs. The development of information technology and mobile devices, as well as the Internet's interactive nature, offer a structure in which consumers act as value co-creators in ways that allow them to express their needs and experiences (Prahalad \& Ramaswamy, 2000; Teixeira et al., 2012). When companies can successfully manage the consumer experience, they can offer benefits by "capturing rich information across all customer interactions with the service provider and even other service providers that support the overall customer activity" (Teixeira et al., 2012, p. 372).

\section{Conceptual framework}

The literature review suggests that in today's networked age, companies can no longer solely provide a produced output to consumers without any consideration of how consumers encounter their offerings, what they value, and what they want to do with these offerings (Ashley \& Tuten, 2014; Hanna, Rohm, \& Crittenden, 2011; Kaplan \& Haenlein, 2010). Therefore, companies must understand the digital space's participatory, co-creative nature. We used the literature review to develop a conceptual framework that reflects our understanding of 
existing literature. First, this study conceptually sequenced the concepts by property and dimension, and confirmed the presence of four drivers: experience, satisfaction, expression, and share. Additionally, our theorized conceptual framework was then implemented by extracting 12 conditions from each driver; the extraction of these drivers and conditions can help companies specify missions and achieve goals, which can consequently help maximize the conceptual framework (Nesman, Batsche, \& Hernandez, 2007). We reach a generalizable conclusion by applying deductive logical reasoning - using Zott and Amit's (2010) theories for the drivers and conditions of value co-creation on social media - then incorporated Solaimani and Bouwman's (2012) work to interpret our findings.

\subsection{Experience (accessibility, availability, and awareness)}

Consumers should experience a product or service firsthand to best understand it. Social media users who want to experience a service can do so without any technical difficulties; for example, a Business.com survey indicates that 55\% of consumers use social media to find information (Giamanco \& Gregoire, 2012). Additionally, another survey from marketing professionals indicates that Twitter, a popular social media platform, is primarily used to increase brand awareness, rather than sales (Bennett, 2014). Therefore, companies must initially ensure that the details of their business offerings, services, or products are available or accessible to prospective social media users. The digital space offers a cost-effective, less labor-intensive way for small firms to produce and reproduce marketing material with fewer time and geographical restrictions (Hennig-Thurau et al., 2010).

Social media and the Internet can be an important medium for small companies or startups, as it can allow them to showcase their brands to future consumers (Burnes \& Choi, 2015). However, start-ups must ensure that their marketers understand the core users of each medium and its characteristics to best utilize diverse social media platforms. Moreover, the decision to use specific types of social media should be based on core business considerations, such as the company's target markets and consumer groups. For instance, Snapchat can be an effective medium for start-ups that target consumers under 24 years of age, as $78 \%$ of US teens between ages 18 to 24 use the medium; this contrasts social media users between ages 25 and 29, as only 54\% of them use Snapchat (Smith \& Anderson, 2018). It can be possible to manage multiple social media platforms with sufficient human and financial resources, although companies lacking such resources must choose the appropriate medium. Prahalad and Ramaswamy (2000, p. 67) argue that "spurred by the web, digitization of content, high speed wired and wireless networks and new user devices and appliances, there is an unprecedented number of touch-points between the firm and the end-user." Therefore, diverse social media websites also offer opportunities to develop brand awareness among their users (Hoffman \& Fodor, 2010).

\subsection{Satisfaction (services, content, and the interface)}

Companies must provide enjoyment to their social media users and satisfy their needs to continue to engage them in their business. This means the company's services, content, or interfaces should clearly benefit consumers while satisfying their needs (Kaplan \& Haenlein, 2010). 
In other words, firms must be able to offer reasons why consumers should continue to return. Providing appropriate and helpful services and content is critical to motivating audiences to remain connected with the business, as motivated consumers demonstrate a much stronger commitment to the brand (Dwivedi, Johnson, Wilkie, \& Araujo-Gil, 2018; Fuller, 2010). The rise of information technology has also enabled intangible innovation, while consumer satisfaction is determined by the types of services or content that companies offer as well as their value to consumers (Lusch \& Nambisan, 2015). Freedom of access to a service or content is also important in the social media age; consumers believe that they do not need to pay for what they consume in the social media space, as many business models are driven by free access.

\subsection{Expression (user creativity, personalization, and customization)}

Capturing users' intrinsic interests is also important in drawing their attention to a business. However, conditions should apply in environments in which users can express their creativity and motivations. Many studies argue that current consumers are no longer passive recipients or destroyers of the value produced by companies; rather, they now take an active role by becoming value co-creators through their own media content, contributing to new products' development, and suggesting new ideas (Lusch \& Vargo, 2014; Ramaswamy \& Ozcan, 2016). One survey has indicated that American teens spend an average of nine hours each day creating and spending their media content (Common Sense Media, 2015). Kaplan and Haenlein (2010) argue that social media is generally built on the Web 2.0 platform, which allows technical, participatory engagement and collaborative activities. Therefore, individual participation unleashes Web 2.0's technical possibilities. Users' participation and engagement are key elements of social media, as these imply "the concept of a 'participation-Internet,' in which users are actively involved in the creation of content" (Matschke, Moskaliuk, \& Cress, 2012, p. 161). Further, users expressing their own personality and needs do not always create their own content expressing their distinctive skills or creativity, as companies can offer simple, easy-to-use tool kits that can be personalized, or other customized service offerings or products (Salvador, De Holan, \& Piller, 2009; Ramaswamy \& Ozcan, 2016).

\subsection{Share (interactivity, connectivity, and reward)}

To share their business and content, firms must understand that the Internet, and social media in particular, is not a technology that they can fully control; rather, it is organized and maintained by users and their desire to share and interact with others. Therefore, firms must accept that they no longer have full control in terms of information generation and sharing (Kaplan \& Haenlein, 2010). Instead, they can offer an environment in which each user is easily connected and can share their passions and interests (Schau, Muniz, \& Arnould, 2009). Research suggests that companies can benefit by allowing this sharing and interaction among users. This is confirmed in various studies, including works by Trusov, Bucklin, and Pauwels (2009), who demonstrated that referrals in online communities improved user acquisition, and Jansen, Zhang, Sobel, and Chowdury (2009), who suggested that users took advantage of social media when making purchasing decisions, and that their brand perceptions were influenced by social networking services. 
Thus, we designed the structure depicted in the below Figure 1 based on these findings. Our drivers consist of 4 elements: experience, satisfaction, expression, and sharing, with 12 conditions. Experience includes accessibility, availability, and awareness; satisfaction includes services, content, and interfaces; expression includes user creativity, personalization, and customization; and finally, sharing ability includes connectivity, interactivity, and reward. Specifically, these drivers evolved in terms of internalizing and externalizing value.

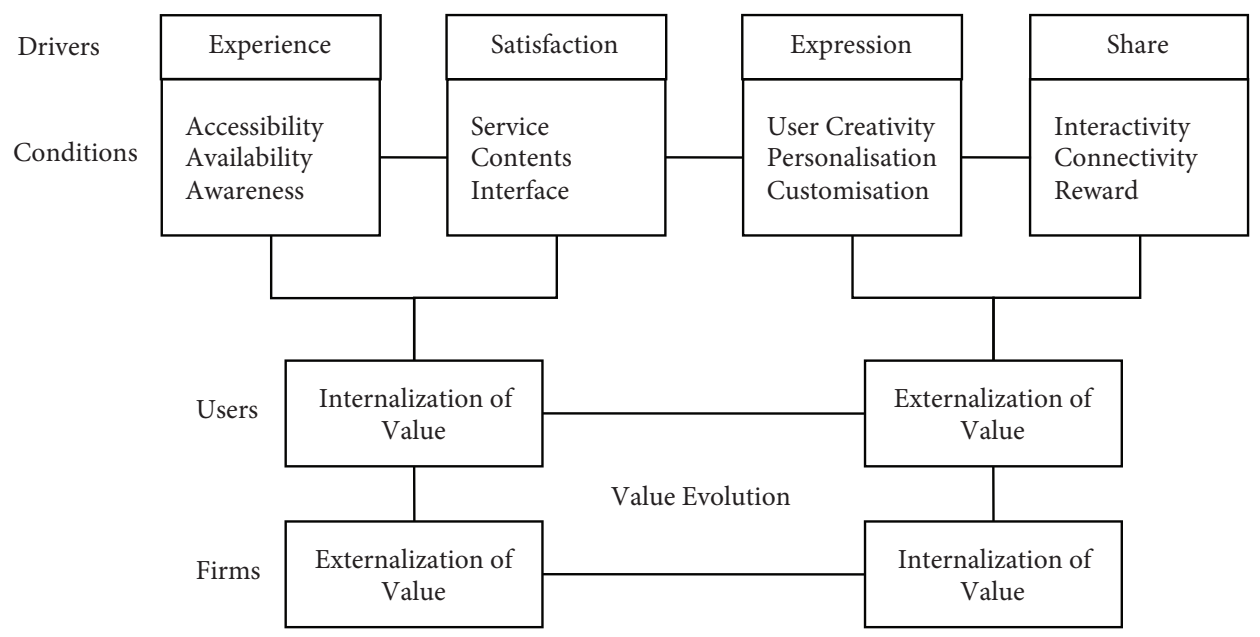

Figure 1. Drivers and conditions of business and value co-creation in social media

\section{Research design and methodological overview}

\subsection{Methodology}

A case study approach is "revelatory" for this research (Yin, 2009). Specifically, RecordFarm an Asian start-up company - appears well-adapted to our research objective, in that the company utilizes its own social media-based business service as well as other social media services to co-create value. Moreover, as an example of an effective social media strategy, RecordFarm successfully reached one million monthly active users after only a year and half of operations without any commercial advertisements. Thus, we argue that our case study is appropriate, and the information can be generalized and used in similar situations. Moreover, as previously mentioned, we did not discover any relevant literature on how startups and SMEs exploit social media users' value creation as a driver of successful social media strategies. Therefore, we chose one strong explanatory case study due to the nature of the research question, which involves 1) how to co-create value through social media, and 2) the drivers of a start-up company's successful social media strategy (Yin, 2009).

We analyzed the RecordFarm case study, which involves a small, relatively young start-up company, by gathering information from multiple sources: direct observations, documents, physical artifacts, and archival records. The primary data sources were semi-structured interviews - conducted at the end of April 2013 with a co-founder and 3 marketing team 
members - and a satisfaction survey of 231 social media users. The study's focus involves investigating and understanding social media users' value-creation process while identifying the drivers of a start-up company's successful social media strategies.

\subsection{Case background}

RecordFarm is an Asian start-up company founded in January 2015, with 10 staff members including the CEO. Additionally, individual musicians work from home on projects closely related to the company. The company is wholly owned by its two co-founders and is strictly centralized. The co-founders make all managerial and technical decisions, contact potential musicians, and manage listener resources. The company's mission is to create an open audio platform and SNS base that enables its users to record, upload, listen, share, and promote their own original audio files. For this purpose, RecordFarm developed a social audio platform prototype service, which was launched in September 2014. After developing the platform, the company faced two problems. First, the nature of the platform required RecordFarm to establish both supply and demand sides (Eisenmann, Parker, \& Van Alstyne, 2006; Kim, 2016). Therefore, the company addressed this issue by using social media; it began by managing five Facebook pages to gather users and initiate a viral marketing campaign. Today, each of these Facebook pages has at least 450,000 followers, and the influx of users from its Facebook pages began to create value for the RecordFarm platform. This strategy exemplifies the "chicken and the egg" problem (Rochet \& Tirole, 2003; Kim, 2018), an endemic problem that start-up companies' platforms often face. As more social media users joined the service, RecordFarm established the platform's demand side, which initiated a cross-marketing process to bring content providers onboard as the supply side. With a successful social media marketing strategy, the company began to add other social media services, such as Instagram, Blogger, and Weibo. Moreover, after building their initial service, the firm began to provide social media services through its own My Page, Newsfeed, Comments, and Timeline service pages for co-creation through social media. RecordFarm executives described the company's social media strategy as follows:

"To save our marketing budget, social marketing is a really great strategy to initially ignite network effects for our platform." - Co-Founder and CTO

"With a successful social media strategy, we decided to provide social media services internally, such as My Page, Newsfeed, Comments, and Timeline, to boost our service through users' interactions." - Head of Marketing

RecordFarm's marketing team primarily relies on social media to gain users, with two critical aspects regarding the company's use of social media. First, although many social media sites exist - such as Twitter, Facebook, Pinterest, Instagram, Foursquare, YouTube, and LinkedIn - RecordFarm only focuses on two: Facebook and YouTube. This is because analyses indicate that the individual musicians who provide content for RecordFarm's platform mostly participate in Facebook and YouTube. Second, RecordFarm initially focused 
on gaining listeners who were consumers, and not on individual musicians who are also content providers. To paraphrase the Head of Marketing, the online music market differs from the existing traditional music market, in that consumers enjoy building communities with each other and sharing information, and musicians enjoy interacting with them. Thus, RecordFarm implemented this strategy by attracting 50,000 users using varied, strong content at the onset, then tried to attract content providers to these communities of initial users. Additionally, RecordFarm cross-marketed user interactions to gain 300,000 active users on social media and attract them to the real RecordFarm service. In other words, RecordFarm chose content providers and content consumers based on the characteristics of the two-sided supply-and-demand market platform. Additionally, it utilized social media interactions to cocreate value. Therefore, the company's social media strategies were key marketing elements that led to its rapid growth.

\section{Results and interpretation}

\subsection{Experience (accessibility, availability, and awareness)}

To understand the user experience, a service should be introduced to consumers in its initial stages, and the service should be easily approachable in this early experience. In its first stage, RecordFarm created Facebook and YouTube pages to introduce and advertise a beta version of its service before launching it officially (See Figure 2). In RecordFarm's case, users have the ability to search and investigate the music they want to listen to and share on the Internet. Most consumers today are generally well-informed about their music, as they use information on product specifications, prices, and substitutes to make their decisions. Specifically, and as in RecordFarm's case, the use of social media can be critical for small firms or startups that have insufficient resources or funds to pursue national or international marketing and promotional activities.

The service experience is also important, as various social media platforms can promote knowledge of the service and brand. Specifically, no significant money is invested with

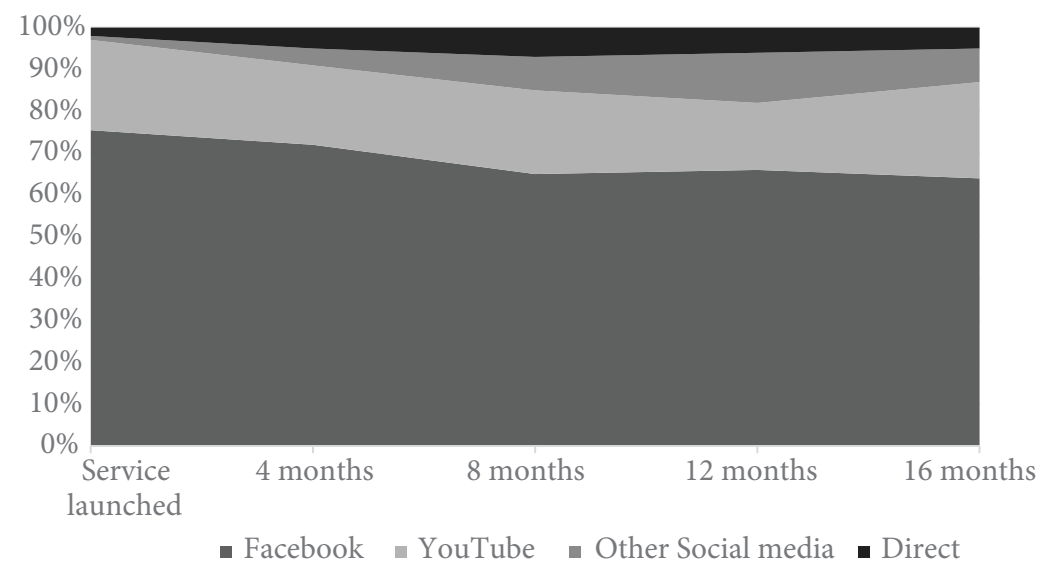

Figure 2. RecordFarm user inflow pattern 
social media channels, but this marketing strategy can be important for startups, as value co-creation with users is an expected benefit. For example, RecordFarm can use these social networking sites to showcase its services and introduce various functions to potential customers. Although these sites only establish indirect contact between RecordFarm's services and potential users, these social networks can be close to consumer aspects of the RecordFarm business and its products (Hoffman \& Fodor, 2010). For instance, part of RecordFarm's strategy involves uploading its users' audio files on Facebook and other social media platforms to display the content. Once on Facebook, this content can gain popularity and initiate a successful viral marketing strategy as the firm's content promotion significantly increases (Dutta, 2010). This will eventually increase direct contact between RecordFarm and its consumers. RecordFarm's early content was produced by individual musicians who were the platform's users, but the company as the platform provider reprocessed and spread this content through its social media. Therefore, this step helped new potential users quickly become familiar with and join the service to participate in these common value creation and production output processes.

\subsection{Satisfaction (services, content, and the interface)}

RecordFarm uses social media to notify users of its new content and artist updates, as well as suggest music based on users' requirements (See Figure 3). The company proactively utilizes social media, as it consistently offers audio content and artist updates. The company is also engaged in constant dialogue and interaction with its users who ask for specific help to address their needs. To answer those users, the company offers not only user services, such as website addresses or telephone numbers where users can obtain the relevant, necessary information, but also detailed, customized answers and solutions for each user.

The advent of information technology has enabled intangible innovation, and today's consumer satisfaction is often determined by the types of service or content that companies offer, and how valuable this is to consumers (Lusch \& Nambisan, 2015). RecordFarm's rapid market growth was possible because it enabled a valuable user experience not offered by any other service provider. RecordFarm users have the "My Page" feature, which enables interactions and communications with other users and gives the latter instant access to their timelines and newsfeeds. Additionally, RecordFarm has pioneered an online-to-offline (O2O) audio

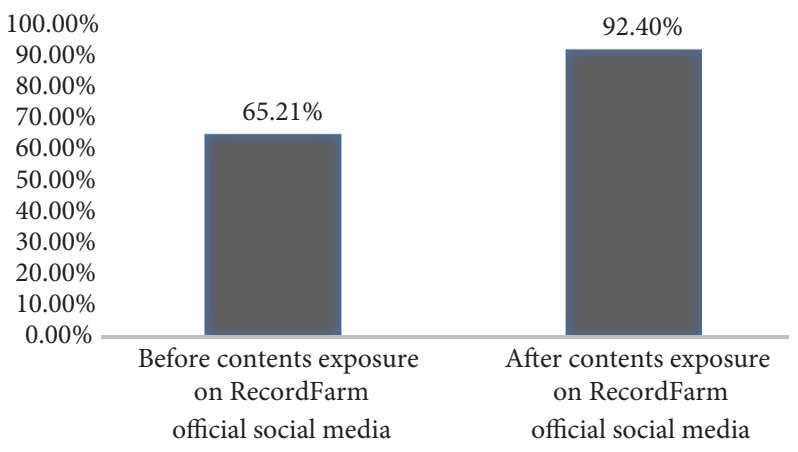

Figure 3. User satisfaction trends 
platform, in which users can create audio for offline event performances, such as busking and concerts. RecordFarm also allows users to access their offline events online, and these files can be accessed on different digital devices, such as laptops, tablets, or mobile phones. Free access to a service or content is also important in the social media age. Users do not necessarily believe that they should have to pay for what they consume in the social media space, as many business models are driven by free access. RecordFarm has a two-pronged strategy, as it offers basic services for free, then charges for more advanced features. In marketing, this is called the "freemium" strategy, in which a basic service is provided free of charge while a price (premium) is charged for proprietary features. Additionally, by continuously managing content and promoting recommended music on social media, RecordFarm has been able to provide better service and satisfaction to its users and extend its service interface through a self-analysis engine.

\subsection{Expression (user creativity, personalization, and customization)}

Past attention has been paid to users' "internalizing of value" as well as firms' "externalizing of value." In contrast, two drivers currently focus on users' "externalizing of value" and firms' "internalizing of value." Consumers are no longer passive in a constantly changing network environment. Further, it is important in this digital age to provide an environment that fosters consumer creativity as individuals are increasingly accustomed to customizing and personalizing everything according to their own tastes.

RecordFarm offers the "My Page" function to allow users to customize and personalize design elements for artists, and provides customized, personalized digital music services for listeners. The service also identifies music based on listeners' music preferences and that fits specific users' needs and profiles, then offers a suggestion service for related music. When the platform offers an environment in which users can create their own value, other competitors cannot imitate it, as it cannot be predicted or replicated by virtue of its roots in the users' personal lives and values. Similarly, the success of businesses that encourage user participation and engagement cannot be mimicked, as their generated content, information, and value is not easily imitable. RecordFarm allows its users to share, discuss, and vote on their own music and audio files through its website and official Facebook page; in doing so, it enables creative, innovative, and user-driven new music content and audio file offerings on its sites, unlike other music streaming services. This makes RecordFarm's content truly distinctive and based on users' needs. Further, its service offerings more closely reflect its users' demands, and RecordFarm's value has increased dramatically by allowing user participation. An internal survey was conducted of its users through online panels comprised of 1,008 random RecordFarm users across 14 countries; the simple satisfaction survey was administered in English, Korean, and Chinese, and its length varied depending on the language, but averaged approximately 5 minutes. This survey revealed that $91.3 \%$ (rounded to the nearest hundredth) of users were "very satisfied" with RecordFarm's service. Notably, RecordFarm received a 4.7 out of 5.0 on Android's Google Play, and achieved strong satisfaction on Apple's iTunes, with a score of 4.81 out of 5.0 . 


\subsection{Share (connectivity, interactivity, and reward)}

As new forms of digital media become more open and offer more autonomy for basic users in terms of communications and interaction, these help to gather consumers and encourage their interaction on topics that they are passionate about. In prior closed Web approaches, in which firms' digital activities were centered on corporate-controlled websites, all communications occurred within these sites, and it was difficult to imagine how this information could be shared with others outside these sites. Jenkins, Ford, and Green (2013) argue that companies today should abandon any traditional sense of the Internet based on its content "stickiness," as this no longer attracts consumers. They assert that although "stickiness" offers a company an easier way to measure statistics, such as views or visits, it does not reflect the true use of digital media today. Therefore, rather than trying to confine user activity through its website content, a company should encourage open participation and the dissemination of its material across diverse social media platforms (Choi \& Burnes, 2017; Green \& Jenkins, 2011). When the user relationship and media are both interconnected and networked, digital content can unexpectedly reach large numbers of people.

By connecting and interacting with peers or corporations, RecordFarm consumers can promote and establish reputations. People primarily participate in social media due to their eagerness to gain personal and social recognition, make positive impressions, and express their identities (Kaplan \& Haenlein, 2010). Moreover, consumers can develop different or advanced knowledge that can be shared with others, which can then serve as a source of learning for others. All information-sharing or interactive activities used to happen within the boundary of the website or community, but information can now move freely from user to user. RecordFarm allows any interested individual to join its community, and subsequently, the associated communication and interactions (See Figure 4). This important strategy allows users to contribute to the RecordFarm services' value co-creation. Clearly, the information and knowledge gained from digital media can be a source of value for users (Payne et al., 2008).

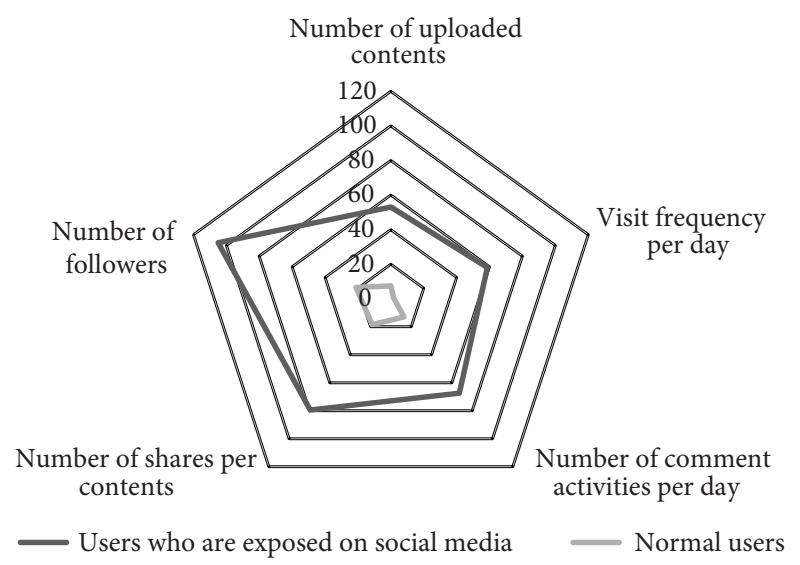

Figure 4. Service use comparison between the users exposed through social media and normal users 
Additionally, RecordFarm uses social media as both a connection and a reward, as it promotes active users on its main page, as well as its official Facebook and YouTube pages, to connect with non-users. Consequently, users actively manage their content to indicate higher loyalty, as they want to receive this exposure as a reward; this allows them to be seen by more than two million other users through this single channel of exposure.

\section{Discussion}

Currently, companies highly value consumers who use social media channels to create and share various types of non-economic value information. The digital space and its user engagement contribute to creating and circulating value, meaning, and consumers' experiences. Further, start-up companies can use social media to interact with their users, gain social knowledge, and innovate in their businesses. They can also access users' value-creation spaces to co-create value with them, and utilize users' contributions to their businesses, which can potentially offer these businesses innovation tasks (Sawhney, Verona, \& Prandelli, 2005). In doing so, companies can use various innovation activities in their businesses, such as detecting their users' problems and needs, developing new products and services, and improving their businesses in general (Blazevic \& Lievens, 2009). Further, Michel, Brown, and Gallan (2008) note that innovation comes not only from the production side, but also from the consumption side; therefore, start-ups' users can also be co-creators, as they contribute their knowledge and resources. In this sense, the author argues that a firm must innovate with its users instead of its products. This is because firms that collaborate with users to create value in virtual spaces can maintain a constant dialogue with these users to gain social knowledge, which can eventually complement traditional one-way interactions with users (Li \& Bernoff, 2008; Sawhney et al., 2005). Empirical research also confirms that firms' adoption of social media and willingness to interact with their customers in this space positively influences product innovation (Bertschek \& Kesler, 2017). Moreover, Sawhney et al. (2005, p. 15) mention that "the various Internet-based collaboration mechanisms are synergistic, and therefore can be employed simultaneously as part of an integrated innovation strategy, and not as independent 'silos' for user dialogue." This opportunity to gain broader user knowledge could increase start-up firms' sustainability and rapid growth, as a firm's competitiveness largely depends on how to leverage external knowledge (Tambe, Hitt, \& Brynjolfsson, 2012) and how to leverage social media to involve users in the innovation process (Bughin, Hung Byers, \& Chui, 2011). Firms now have an opportunity to interact with users and collect vast amounts of user-generated information, but the questions must now involve how to administer an interactive process with users and stimulate users in the value co-creation process.

Previous research suggests that managing and enabling inbound and outbound customerto-customer dialogue is important for firms in the social media age (Gallaugher \& Ransbotham, 2010). Social media that allows firms to strengthen interactions and dialogue with their customers and monitor the communication between customers can provide a critical source of innovation for firms (Cheng \& Shiu, 2018). However, what has been less clear is how startups can effectively engage with and utilize social media to coordinate users' cooperation and co-create value. Our research also indicates that value collectively forms and evolves over 
the course of this co-creation. Managing social media without users' engagement may fail to demonstrate the medium's real benefits. Further, the current digital environment suggests that value creation is not entirely managed by firms; rather, the value of user engagement is critical to successfully organizing value co-creation. Therefore, firms must understand that the decision to utilize social media requires an understanding, in that their strategic social media approach becomes an organic element in the entire social media system (Martini, Massa, \& Testa, 2013). Firms now can enjoy an environment in which user engagement has become ordinary, and generating user-created information and ideas is an important source for firms (Dong \& Wu, 2015). As this article suggests, firms that want to innovate must develop social media capabilities and strategies, as this can convey any comments or suggestions regarding the innovation, and other users can share and collaborate in the innovation process. This innovation management process can then foster the evolution and co-creation of value between firms and their customers. Thus, firms' success in the digital age may depend on their users' levels of engagement in the business and innovation process, as well as the successful organization of co-creation.

Although a firm assumption has been that managing user engagement in the digital space allows the firm to gain business value, studies have not thoroughly addressed how this can be achieved (Dong \& Wu, 2015). Many firms now establish a social media presence to adapt to changing business communications and customer relationship environments. However, one problem with this approach is that the focus has been on how to effectively disseminate their marketing messages, rather than how to effectively collaborate with users or customers to realize social media's full potential in value co-creation and innovation. This article clearly posits that utilizing social media should not merely focus on a firm's promotional activities, but rather, the ultimate goal of engaging in a social media space should involve organizing an effective business process to efficiently engage users, who are now regarded as important contributors to value creation. Additionally, we believe that this is particularly suitable for start-up companies that may lack human and financial resources, which can cause them difficulty in conducting luxurious market research to understand market changes and needs.

\section{Conclusions}

Many start-up companies fail before their fifth year due to weak business and marketing strategies, as well as limited resources (Solaimani \& Bouwman, 2012). Our investigation of a strong single case study revealed the user value-creation process as well as the company's drivers of successful social media strategies. This study presents a conceptual framework that consists of four core drivers - experience, satisfaction, expression, and sharing ability which in turn contain many conditions. Three important conditions must be considered regarding experience as a driver: accessibility, availability, and awareness. Users must experience a product or service firsthand to understand what it involves. Therefore, companies should ensure that their business offerings, services, or products are available and accessible to prospective users. Satisfaction as a driver includes the service, content, and interface conditions. The business must create enjoyment and satisfy needs to continue to engage users in experiencing its offerings. Further, a firm must present reasons why consumers should 
continue to return by providing appropriate, helpful services or content, as these are critical to motivating audiences to stay with the business. Expression as a driver includes user creativity, personalization, and customization as conditions. Consumers are no longer passive recipients of social media, which is built on the Web 2.0 platform; this technically allows users' participatory engagement and collaborative activities, unleashing its technical potential. Sharing ability as a driver includes the conditions of connectivity, interactivity, and reward. Companies must accept that they can no longer fully control information generation and sharing, and must instead offer an environment in which each user can easily connect to share their passions and interests.

This study identifies core drivers and conditions to help firms - and especially start-ups understand and utilize social media in developing their businesses. Social media allows users and firms to evaluate value, both internally and externally. Moreover, start-up companies regard users who incorporate social media channels to create and share various types of noneconomic value as important participants. Therefore, start-up companies can interact with their users to gain social knowledge and access the users' value-creation spaces to co-create value with them. This study's findings are relevant for those in academia who aim to understand not only the core drivers and conditions of business and value co-creation through social media, but also how value co-creation through social media is linked to companies. This link is currently underexplored in social media research (Edvardsson et al., 2011; SeeTo \& Ho, 2014). Additionally, these findings are useful for practitioners attempting to use the framework in their own businesses.

The results from this case study of a single company might not be generalizable. Thus, this study does not apply to all start-up companies, although it enables an understanding of users' value creation processes and the drivers of a small company's successful social media strategy.

\section{Acknowledgements}

The authors thank the anonymous reviewers and editor for their valuable contributions.

\section{Funding}

This research received no specific grant from any funding agency in the public, commercial, or not-for-profit sectors.

\section{References}

Aral, S., \& Weill, P. (2013). IT assets, organizational capabilities, and firm performance: How resource allocations and organizational differences explain performance variation. Organization Science, 18(5), 763-780. https://doi.org/10.1287/orsc.1070.0306

Ashley, C., \& Tuten, T. (2014). Creative strategies in social media marketing: An exploratory study of branded social content and consumer engagement. Psychology \& Marketing, 32(1), 15-27. https://doi.org/10.1002/mar.20761

Atanassova, I., \& Clark, L. (2015). Social media practices in SME marketing activities: A theoretical framework and research agenda. Journal of Customer Behaviour, 14(2), 163-183. https://doi.org/10.1362/147539215X14373846805824 
Bennett, S. (2014). Brands use Twitter to boost awareness. Retrieved from http://www.adweek.com/ digital/twitter-brands-awareness-sales/

Bernoff, J., \& Schadler, T. (2010). Empowered: Unleash your employees, energize your customers, transform your business. Harvard Business Review Press.

Bertschek, I., \& Kesler, R. (2017). Let the user speak: Is feedback on Facebook a source of firms' innovation? (ZEW Discussion Paper No. 17-015). Retrieved from http://ftp.zew.de/pub/zew-docs/dp/ dp17015.pdf

Blazevic, V., \& Lievens, A. (2008). Managing innovation through customer coproduced knowledge in electronic services: an exploratory study. Journal of the Academy of Marketing Science, 36(1), 138151. https://doi.org/ 10.1007/s11747-007-0064-y

Brodie, R. J., Ilic, A., Juric, B., \& Hollebeek, L. D. (2013). Consumer engagement in a virtual brand community: An exploratory analysis. Journal of Business Research, 66(1), 105-114. https://doi.org/10.1016/j.jbusres.2011.07.029

Bughin, J., Hung Byers, A., \& Chui, M. (2011). How social technologies are extending the organization. McKinsey Quarterly. Retrieved from http://www.mckinsey.com/industries/high-tech/our-insights/ how-social-technologies-are-extending-the-organization

Burnes, B., \& Choi, H. (2015). Future cities and self-organising value chains: The case of the independent music community in Seoul. Supply Chain Management: An International Journal, 20(3), 300-312. https://doi.org/10.1108/SCM-04-2014-0141

Cavusgil, S. T., \& Knight, G. (2015). The born global firm: An entrepreneurial and capabilities perspective on early and rapid internationalization. Journal of International Business Studies, 46(1), 3-16. https://doi.org/10.1057/jibs.2014.62

Ceccagnoli, M., Forman, C., Huang, P., \& Wu, D. J. (2011). Co-creation of value in a platform ecosystem! The case of enterprise software. MIS Quarterly, 36, 263-290. https://doi.org/10.2307/41410417

Cheng, C., \& Shiu, E. (2018). How to enhance SMEs' customer involvement using social media: The role of social CRM. International Small Business Journal: Researching Entrepreneurship. https://doi.org/10.1177/0266242618774831

Choi, H., \& Burnes, B. (2013). The Internet and value co-creation: The case of the popular music industry. Prometheus, 31(1), 35-53. https://doi.org/10.1080/08109028.2013.774595

Choi, H., \& Burnes, B. (2017). Bonding and spreading: Co-creative relationships and interaction with consumers in South Korea’s indie music industry. Management Decision, 55(9), 1905-1923. https://doi.org/10.1108/MD-10-2010691

Common Sense Media. (2015). U.S. teens use an average of nine hours of media per day. Retrieved from https://www.commonsensemedia.org/about-us/news/press-releases/landmark-report-us-teens-usean-average-of-nine-hours-of-media-per-day

Dimitriu, R., \& Guesalaga, R. (2017). Consumers' social media brand behaviors: Uncovering underlying motivators and deriving meaningful consumer segments. Psychology \& Marketing, 34(5), 580-592. https://doi.org/10.1002/mar.21007

Dong, J. Q., \& Wu, W. (2015). Business value of social media technologies: Evidence from online user innovation communities. The Journal of Strategic Information Systems, 24(2), 113-127. https://doi.org/10.1016/j.jsis.2015.04.003

Dutta, S. (2010). What's your personal social media strategy? Harvard Business Review, 88(11), 127-130.

Dwivedi, A., Johnson, L. W., Wilkie, D., \& Araujo-Gil, L. (2018). Consumer emotional brand attachment with social media brands and social media brand equity. European Journal of Marketing. https://doi.org/10.1108/EJM-09-2016-0511

Edelman, D. (2010). Branding in the digital age: You're spending your money in all the wrong places. Harvard Business Review, 88(12), 62-69. 
Edvardsson, B., Tronvoll, B., \& Gruber, T. (2011). Expanding understanding of service exchange and value co-creation: A social construction approach. Journal of the Academy of Marketing Science, 39(2), 327-339. https://doi.org/10.1007/s11747-010-0200-y

Eisenmann, T., Parker, G., \& Van Alstyne, M. W. (2006). Strategies for two-sided markets. Harvard Business Review, 84(10), 92.

Fischer, E., \& Reuber, A. R. (2011). Social interaction via new social media: (How) can interactions on Twitter affect effectual thinking and behavior? Journal of Business Venturing, 26(1), 1-18. https://doi.org/10.1016/j.jbusvent.2010.09.002

Fuller, J. (2010). Refining virtual co-creation from a consumer perspective. California Management Review, 52(2), 98-122. https://doi.org/10.1525/cmr.2010.52.2.98

Gallaugher, J., \& Ransbotham, S. (2010). Social media and customer dialog management at Starbucks. MIS Quarterly Executive, 9(4), 197-212.

Ghezzi, A., Gastaldi, L., Lettieri, E., Martini, A., \& Corso, M. (2016). A role for startups in unleashing the disruptive power of social media. International Journal of Information Management, 36(6), 1152-1159. https://doi.org/10.1016/j.ijinfomgt.2016.04.007

Giamanco, B., \& Gregoire, K. (2012). Tweet me, friend me, make me buy. Harvard Business Review, 90(7), 89-93.

Green, J., \& Jenkins, H. (2011). Spreadable media: how audiences create value and meaning in a networked economy. In V. Nightingale (Ed.), The handbook of media audiences (pp. 119-126). Blackwell Publishing Ltd. https://doi.org/10.1002/9781444340525.ch5

Hanna, R., Rohm, A., \& Crittenden, V. (2011). We're all connected: The power of the social media ecosystem. Business Horizons, 54(3), 265-273. https://doi.org/10.1016/j.bushor.2011.01.007

Helkkula, A., Kelleher, C., \& Pihlström, M. (2012). Characterizing value as an experience: Implications for service researchers and managers. Journal of Service Research, 15(1), 59-75. https://doi.org/10.1177/1094670511426897

Hennig-Thurau, T., Malthouse, E. C., Friege, C., Gensler, S., Lobschat, L., Rangaswamy, A., \& Skiera, B. (2010). The impact of new media on user relationships. Journal of Service Research, 13(3), 311-330. https://doi.org/10.1177/1094670510375460

Hoffman, D. L., \& Fodor, M. (2010). Can you measure the ROI of your social media marketing? MIT Sloan Management Review, 52(1), 41-49.

Hollebeek, L., Glynn, M., \& Brodie, R. (2014). Consumer brand engagement in social media: Conceptualization, scale development and validation. Journal of Interactive Marketing, 28(2), 149-165. https://doi.org/10.1016/j.intmar.2013.12.002

Jansen, B. J., Zhang, M., Sobel, K., \& Chowdury, A. (2009). Twitter power: Tweets as electronic word of mouth. Journal of the American Society for Information Science and Technology, 60(11), 2169-2188. https://doi.org/10.1002/asi.21149

Jenkins, H., Ford, S., \& Green, J. (2013). Spreadable media: creating value and meaning in a networked culture. New York University Press.

Kaplan, A., \& Haenlein, M. (2010). Users of the world, unite! The challenges and opportunities of social media. Business Horizons, 53(1), 59-68. https://doi.org/10.1016/j.bushor.2009.09.003

Kim, J. (2016). The platform business model and business ecosystem: Quality management and revenue structures. European Planning Studies, 24(12), 2113-2132. https://doi.org/10.1080/09654313.2016.1251882

Kim, J. (2018). Market entry strategy for a digital platform provider. Baltic Journal of Management, 13(3), 390-406. https://doi.org/10.1108/bjm-07-2017-0228

Kohli, R., \& Grover, V. (2008). Business value of IT: An essay on expanding research directions to keep 
up with the times. Journal of the Association for Information Systems, 9(1), 23-39. https://doi.org/10.17705/1jais.00147

Lee, M., Lee, M., \& Kim, J. (2017). A dynamic approach to the start-up business ecosystem: A crosscomparison of Korea, China, and Japan. Asian Academy of Management Journal, 22(2), 157-184. https://doi.org/10.21315/aamj2017.22.2.6

Li, C., \& Bernoff, J. (2008). Groundswell: winning in a world transformed by social technologies. Harvard Business Press.

Lusch, R., \& Nambisan, S. (2015). Service innovation: A service-dominant logic perspective. MIS Quarterly, 39(1), 155-175. https://doi.org/10.25300/MISQ/2015/39.1.07

Lusch, R., \& Vargo, S. (2014). Service-dominant logic: premises, perspectives, possibilities. Cambridge University Press.

Mangold, G., \& Faulds, D. (2009). Social media: The new hybrid element of the promotion mix. Business Horizons, 52(4), 357-365. https://doi.org/10.1016/j.bushor.2009.03.002

Martini, A., Massa, S., \& Testa, S. (2013). The firm, the platform and the customer: A "double mangle" interpretation of social media for innovation. Information and Organization, 23(3), 198-213. https://doi.org/10.1016/j.infoandorg.2013.07.001

Matschke, C., Moskaliuk, J., \& Cress, U. (2012). Knowledge exchange using Web 2.0 technologies in NGOs. Journal of Knowledge Management, 16(1), 159-176. https://doi.org/10.1108/13673271211199007

Michel, S., Brown, S. W., \& Gallan, A. S. (2008). Service-logic innovations: How to innovate customers, not products. California Management Review, 50(3), 49-65. https://doi.org/10.2307/41166445

Mount, M., \& Martinez, M. G. (2014). Social media: A tool for open innovation. California Management Review, 56(4), 124-143. https://doi.org/10.1525/cmr.2014.56.4.124

Nesman, T. M., Batsche, C., \& Hernandez, M. (2007). Theory-based evaluation of a comprehensive Latino education initiative: An interactive evaluation approach. Evaluation and Program Planning, 30(3), 267-281. https://doi.org/10.1016/j.evalprogplan.2007.04.004

Ngai, E. W., Tao, S. S., \& Moon, K. K. (2015). Social media research: Theories, constructs and conceptual frameworks. International Journal of Information Management, 35(1), 33-44. https://doi.org/10.1016/j.ijinfomgt.2014.09.004

Oh, C., Roumani, Y., Nwankpa, J., \& Hu, H. (2017). Beyond likes and tweets: Consumer engagement behavior and movie box office in social media. Information \& Management, 54(1), 25-37. https://doi.org/10.1016/j.im.2016.03.004

Papagiannidis, S., \& Bourlakis, M. (2015). Social media: A revolution in communication. Technological Forecasting and Social Change, 95, 1-2. https://doi.org/10.1016/j.techfore.2014.09.011

Payne, A. F., Storbacka, K., \& Frow, P. (2008). Managing the co-creation of value. Journal of the Academy of Marketing Science, 36(1), 83-96. https://doi.org/10.1007/s11747-007-0070-0

Perlberg, S. (2015). How Netflix is shaking up its marketing strategy. Retrieved from https://blogs.wsj. $\mathrm{com} / \mathrm{cmo} / 2015 / 04 / 16 /$ netflix-marketing-strategy/

Polese, F., Mele, C., \& Gummesson, E. (2017). Value co-creation as a complex adaptive process. Journal of Service Theory and Practice, 27(5), 926-929. https://doi.org/10.1108/JSTP-07-2017-0111

Prahalad, C. K., \& Ramaswamy, V. (2000). Co-opting customer competence. Harvard Business Review, 78(1), 79-90.

Prahalad, C. K., \& Ramaswamy, V. (2004). Co-creation experiences: The next practice in value creation. Journal of Interactive Marketing, 18(3), 5-14. https://doi.org/10.1002/dir.20015

Ramaswamy, V., \& Ozcan, K. (2016). Brand value co-creation in a digitalized world: An integrative framework and research implications. International Journal of Research in Marketing, 33(1), 93-106. https://doi.org/10.1016/j.ijresmar.2015.07.001 
Rathore, A. K., Ilavarasan, P. V., \& Dwiedi, Y. (2016). Social media content and product co-creation: An emerging paradigm. Journal of Enterprise Information Management, 29(1), 7-18. https://doi.org/10.1108/JEIM-06-2015-0047

Rochet, J., \& Tirole, J. (2003). Platform competition in two-sided markets. Journal of the European Economic Association, 1(4), 990-1029. https://doi.org/10.1162/154247603322493212

Salvador, F., De Holan, P., \& Piller, F. (2009). Cracking the code of mass customization. MIT Sloan Management Review, 50(3), 71-78.

Sawhney, M., Verona, G., \& Prandelli, E. (2005). Collaborating to create: The Internet as a platform for customer engagement in production innovation. Journal of Interactive Marketing, 19(4), 4-17. https://doi.org/10.1002/dir.20046

Schau, H. J., Muniz, A. M., \& Arnould, E. J. (2009). How brand community practices create value. Journal of Marketing, 73(5), 30-51. https://doi.org/10.1509/jmkg.73.5.30

See-To, E. W., \& Ho, K. K. (2014). Value co-creation and purchase intention in social network sites: The role of electronic word-of-mouth and trust - A theoretical analysis. Computers in Human Behavior, 31, 182-189. https://doi.org/10.1016/j.chb.2013.10.013

Smith, A., \& Anderson, M. (2018). Social media use 2018: demographics and statistics. Retrieved from http://www.pewinternet.org/2018/03/01/social-media-use-in-2018/

Solaimani, S., \& Bouwman, H. (2012). A framework for the alignment of business model and business processes: A generic model for trans-sector innovation. Business Process Management Journal, 18(4), 655-679. https://doi.org/10.1108/14637151211253783

Swaminathan, V., \& Moorman, C. (2009). Marketing alliances, firm networks, and firm value creation. Journal of Marketing, 73(5), 52-69. https://doi.org/10.1509/jmkg.73.5.52

Tambe, P., Hitt, L., \& Brynjolfsson, E. (2012). The extroverted firm: How external information practices affect innovation and productivity. Management Science, 58(5), 843-859.

https://doi.org/10.1287/mnsc.1110.1446

Teixeira, J., Patricio, L., Nunes, N. J., Nobrega, L., Fisk, R. P., \& Constantine, L. (2012). Customer experience modeling: From customer experience to service design. Journal of Service Management, 23(3), 362-376. https://doi.org/10.1108/09564231211248453

Trainor, K. J., Andzulis, J., Rapp, A., \& Agnihotri, R. (2014). Social media technology usage and customer relationship performance: A capabilities-based examination of social CRM. Journal of Business Research, 67(6), 1201-1208. https://doi.org/10.1016/j.jbusres.2013.05.002

Trusov, M., Bucklin, R. E., \& Pauwels, K. (2009). Effects of word-of-mouth versus traditional marketing: Findings from an Internet social networking site. Journal of Marketing, 73(5), 90-102. https://doi.org/10.1509/jmkg.73.5.90

Williams, D. (2017). 4 content marketing lessons to learn from Netflix. Retrieved from https://www. entrepreneur.com/article/294050

Yin, R. K. (2009). Case study research: design and methods (4th ed.). London: SAGE Publications.

Zott, C., \& Amit, R. (2010). Business model design: An activity system perspective. Long Range Planning, 43(2-3), 216-226. https://doi.org/10.1016/j.lrp.2009.07.004 